\title{
Experimental study of newly described avian malaria parasite Plasmodium (Novyella) collidatum n. sp., genetic lineage pFANTAIL01 obtained from South Asian migrant bird
}

\author{
Elena Platonova ${ }^{1,2^{*}} \mathbb{1}$, Justè Aželytè ${ }^{2}$, Tatjana lezhova ${ }^{2}$, Mikas Ilgūnas ${ }^{2}$, Andrey Mukhin $^{1}$ and Vaidas Palinauskas ${ }^{2}$
}

\begin{abstract}
Background: Avian malaria parasites are microorganisms parasitizing erythrocytes and various tissues of the birds; they are common and distributed worldwide. These parasites are known to infect birds of different taxa and be the cause of the deaths of birds in the wild and in captivity. The species of parasites with the ability to colonize new territories and infect local non-migratory birds are of particular interest. This scenario is likely in temperate zones of Europe, because of climate change and its contribution in spreading vectors of southern origin, which can be involved in the transmission of malaria parasites. In the present study, a tropical Plasmodium parasite from a naturally infected long-distance migrant bird was isolated and tested for its ability to develop in common species of mosquitoes and European short-distance migrant birds.

Methods: Plasmodium sp. (pFANTAIL01) was isolated on the Curonian spit of the Baltic sea coast from the naturally infected Common rosefinch, Carpodacus erythrinus in June 2019. The parasite was described based on the morphological features of its blood stages, the partial mitochondrial cytochrome $b$ gene and development after experimental infection of birds and mosquitoes. The parasite was inoculated into Eurasian siskins, Carduelis spinus. Parasitaemia, haematocrit and weight of birds were monitored. At the end of the survey, internal organs were collected to study exoerythrocytic stages of this parasite. Experimental infection of mosquitoes Culex pipiens form molestus and Culex quinquefasciatus was applied to study sporogonic development of the parasite.
\end{abstract}

Results: Based on morphological features, the parasite was described as a new species, Plasmodium collidatum $\mathrm{n}$. sp., and attributed to subgenus Novyella. It was revealed that the obtained PFANTAIL01 lineage is a generalist parasite infecting a wide range of avian hosts and most likely is transmitted in South and Southeast (SE) Asia and Oceania. In Europe, this strain was recorded only in adult migratory birds wintering in South Asia. This parasite developed high parasitaemia in experimentally infected siskins and caused $25 \%$ mortality. Exoerythrocytic stages of pFANTAIL01 were found in the lungs, liver, spleen and kidney of the deceased birds. Sporogonic development did not occur in CX. pipiens form molestus and Cx. quinquefasciatus mosquitoes.

Conclusions: Plasmodium collidatum is a highly virulent for Eurasian siskin and completes its development in these birds, which can be considered as a potential vertebrate host if the transmission of the infection starts occurring in Europe and temperate zones.

\footnotetext{
*Correspondence: plat.992@gmail.com

${ }^{1}$ Biological Station Rybachy of the Zoological Institute, Russian Academy of Sciences, Kaliningrad Region 238535 Rybachy, Russia
}

Full list of author information is available at the end of the article

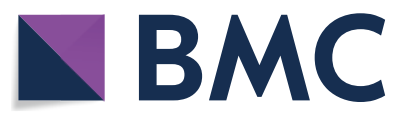

(c) The Author(s) 2021. This article is licensed under a Creative Commons Attribution 4.0 International License, which permits use, sharing, adaptation, distribution and reproduction in any medium or format, as long as you give appropriate credit to the original author(s) and the source, provide a link to the Creative Commons licence, and indicate if changes were made. The images or other third party material in this article are included in the article's Creative Commons licence, unless indicated otherwise in a credit line to the material. If material is not included in the article's Creative Commons licence and your intended use is not permitted by statutory regulation or exceeds the permitted use, you will need to obtain permission directly from the copyright holder. To view a copy of this licence, visit http://creativeco mmons.org/licenses/by/4.0/. The Creative Commons Public Domain Dedication waiver (http://creativecommons.org/publicdomain/ zero/1.0/) applies to the data made available in this article, unless otherwise stated in a credit line to the data. 
Keywords: Plasmodium, Avian malaria, pFANTAIL01, Experimental infection, Rosefinch

\section{Background}

Every year billions of European breeding birds migrate to their wintering ground [1]. The distances the individuals cover along their routes can reach thousands of kilometres and inevitably these movements involve birds as reservoirs in transporting and potentially spreading other organisms to the new territories [2, $3]$. One group of parasites whose spreading can be enforced by migrating birds causes avian malaria. These parasites belong to Plasmodiidae (order: Haemosporida), are distributed worldwide and are diverse [4]. More than 100 years of studies on Plasmodium infecting birds show that some species are virulent to their vertebrate hosts and may cause severe disease [4-10]. Extensive molecular screening of juvenile and adult birds as well as migrant and non-migrating species of birds in Europe reveals which avian malarial parasites are transmitted within Europe and which are exotic species present only in birds after their return from wintering quarters [11]. Among the latter are Plasmodium delichoni (genetic lineage pCOLL6), Plasmodium homonucleophilum (pSW2), Plasmodium homocircumflexum (pCOLL4), Plasmodium ashfordi (pGRW2), and some others [12-15]. This is only a small fraction of all recorded Plasmodium genetic lineages, which are linked to morphologically described species and contains information about their development and virulence for a vertebrate host. In most of the cases, natural vectors are still unknown.

Transmission of the largest number of potentially invasive avian Plasmodium lineages found in Europe, occurs in Africa as this is the main wintering ground for the European long-distance migrant birds [4]. Instead of Africa, several bird species migrate to South Asia and SE Asia, these include Common rosefinch ( $\mathrm{Ca}$. erythrinus), Rosy starling (Pastor roseus), Little bunting (Emberiza pussila), Read-breasted flycatcher (Ficedula parva), Blyths reed warbler (Acrocephalus dumetorum) and a few others [16]. According to the MalAvi database [17], there are more than 20 genetic lineages of avian malarial parasites found in breeding European birds which migrate to South Asia and SE Asia, but only few morphologically described lineages of Plasmodium have been identified, e.g. Plasmodium circumflexum, pTURDUS1 [18, 19], and Plasmodium relictum, pSGS1 [20] and pGRW4 [21]. At present, there are no described malarial parasite lineages linked to Plasmodium species, which are transmitted only in South Asia or SE Asia and annually brought to Europe with migrating birds. However, these parasites should be of prime interest as they may become the main threat to local bird populations in the near future. According to some calculations, the prevalence of avian malaria will increase by two-threefold due to global warming [22]. Ecological changes and invasive mosquito species may play the main role in the appearance of new interactions between invasive mosquito species and exotic Plasmodium parasites causing the transmission of these parasites on local, non-migrating or within Europe migrating birds. For instance, the invasive Asian tiger mosquito (Aedes albopictus), originated from SE Asia, is spreading in some parts of Europe already [23, 24]. The presence of Plasmodium vaughani (genetic lineage pSYAT05) DNA was recorded in these mosquitoes collected in Italy [24] and this mosquito could also be a potential vector for other avian malaria parasites, especially those originated from SE Asia [25].

The development and virulence in a vertebrate host and insect vector vary between different Plasmodium species and, therefore, identification of the parasite species and knowledge about their biology is crucial to better understand the epizootiology and potential spread of avian malaria. In recent years, the description of newly found avian malaria parasites includes both morphological and phylogenetic information obtained from the molecular examination [13, 15, 26, 27]. Some studies go further and provide information about the development patterns in a vertebrate host, erythrocytic and exoerythrocytic stages, the virulence and information about potential vectors $[9$, $10,12]$.

In the present study, a new species of malaria parasite obtained from a naturally infected long-distance migrant Common rosefinch (wintering in South Asia) in Northern Europe was described. Using morphological and molecular methods the detailed description of blood stages and the phylogenetic relationships of this lineage with other previously described avian malaria parasites is provided. The development in the red blood cells (RBCs) and various tissues together with the caused virulence to the vertebrate hosts was studied on common bird species Eurasian siskins Cr. spinus, which migrate within Europe. Sporogonic development of the newly described species was studied in blood sucking mosquitoes $C x$. pipiens form molestus and $C x$. quinquefasciatus. The obtained data can help understanding new parasite-host associations and impact on the host health in regard to parasite spread, brought on by global climate change and newly formed ecological conditions. 


\section{Methods}

\section{Study site and design of the experiment}

In June of 2019, one adult male Common rosefinch was caught using mist-nets on the Curonian Spit of the Baltic Sea $\left(55^{\circ} 09^{\prime} 14 \mathrm{~N}, 20^{\circ} 51^{\prime} 27 \mathrm{E}\right)$ at the Biological station "Rybachy" of the Zoological Institute of the Russian Academy of Science (Russia). The blood was collected in heparinized microcapillary by puncturing a brachial vein. Two blood smears were prepared and stained as described by Valkiūnas [4]; about $25-30 \mu \mathrm{L}$ of blood was stored in SET-buffer (0.05 M Tris, $0.15 \mathrm{M} \mathrm{NaCl}, 0.5 \mathrm{M}$ EDTA, pH 8.0) for a later molecular analysis. Microscopic examination showed a Plasmodium (Novyella) sp. infection. The strain was multiplied in one Eurasian siskin by subinoculation of infected blood as described below for studying experimental infection in the vertebrate host. Juvenile Eurasian siskins, a common and widespread in Europe passerine bird, were used. All wild siskins used in the present experiment were captured about $40 \mathrm{~km}$ away from the biological station. The mist-nets were established in a mixed forest area near the town Zelenogradsk in the vicinity of Zelenogradka river (54 $56^{\prime} 41 \mathrm{~N}$; 20 $30^{\prime} 57$ E). In all, 18 juvenile siskins were captured and randomly allocated to experimental ( 8 birds) and control (10 birds) groups after microscopically proving the absence of Plasmodium parasites in their blood samples. All birds were checked before experimental infection for haemosporidian parasites using microscopic examination (see chapter below). Later, in the laboratory, blood samples obtained from all birds before the experiment and in the end of the experiment were analysed using PCR-based method (as described below). Experimental birds were housed in individual cages $(60 \times 40 \times 40 \mathrm{~cm}$, Joko $\mathrm{GmbH}$, Germany) and kept in a vector-free aviary under controlled laboratory conditions (room temperature $22 \pm 1{ }^{\circ} \mathrm{C}$, photoperiod 17:7 of light:dark). Food and water were provided $a d$ libitum during the entire period of the experiment.

To infect experimental birds, standard protocol in accordance with Palinauskas et al. [28] was used. Each experimental bird was subinoculated with a mixture $(0.10 \mathrm{~mL})$ of infected blood, $3.7 \%$ sodium citrate and $0.9 \%$ saline in proportion 4:1:5 into the pectoral muscles. Intensity of meronts in the two used donor birds were $0.03 \%$ and $0.05 \%$. Two birds were inoculated with approximately $5 \times 10^{4}$ number of mature meronts, and six birds received about $8.3 \times 10^{4}$ meronts. Birds from the negative control group were inoculated using the same procedure and blood mixture as the experimental group, but with blood obtained from an uninfected siskin. The duration of the experiment was 36 days. To estimate the development of parasites in the blood the exposed birds were examined every 4 days by taking blood from the brachial vein as was described above. Small drop of blood was used to make smears for microscopy, a fraction of blood $(20-30 \mu \mathrm{L})$ was placed in SET-buffer for the molecular analysis and the rest (about $30 \mu \mathrm{L}$ ) was used to measure haematocrit level. To measure the haematocrit level, blood collected in capillary was centrifuged for 5 min at 7000 r. p. m using a ELMI CM-70 (ELMI Ltd., Latvia) centrifuge. Also, the body mass was measured in both experimental and control siskins.

At the end of the experiment all experimentally infected birds were euthanized. Their internal organs (the brain, heart, lungs, spleen, liver, kidneys, pectoral muscle) were extracted and placed to a $10 \%$ neutral buffered formalin solution for fixation. Fixed and parafilmembedded tissues were cut in $4 \mu \mathrm{m}$ sections, stained with haematoxylin-eosin ( $\mathrm{H} \& \mathrm{E})$ and examined microscopically under $1000 \times$ magnification $[4,10]$ for parasite's exoerythrocytic stages. Also smears of the bone marrow from bird's femurs were prepared. Air-dried films were fixed in absolute methanol for $3 \mathrm{~min}$ and stained using Romanowski-Giemsa protocol to check the presence of phanerozoites [4].

\section{Experimental infection of mosquitoes}

To study the development of the new malarial parasite in an invertebrate host, two species of potential vectors, $C x$. pipiens form molestus and Cx. quinquefasciatus were used.

Experimental colonies of mosquitoes were established at the Biological Station Rybachy in April 2019. The eggs of mosquitoes were obtained from P. B. Šivickis Laboratory of Parasitology, Nature Research Centre, Vilnius, Lithuania. Insects were kept in isolated laboratory under controlled conditions (room temperature $23 \pm 1{ }^{\circ} \mathrm{C}$; humidity 75-80\%; photoperiod 17:7 light:dark). Mosquitoes were kept in a nylon netted cage $(45 \times 45 \times 45 \mathrm{~cm}$, BugDorm, UK). Food for mosquitoes was provided in the form of cotton wools saturated with $5 \%$ saccharose solution [29].

For experimental infection an infected donor bird with approximate, 1\% parasitaemia (gametocytaemia around $0.3 \%$ ) was used. A bird was carefully immobilized and fixed in a paper tube, leaving only its legs exposed for the mosquitoes [29]. This tube was placed into a separate mosquito cage with about 100 uninfected female mosquitoes taken from the main colony. After $1 \mathrm{~h}$ engorged mosquitoes were separated into small cages $(17.4 \times 17.5 \times 17.5 \mathrm{~cm})$ and kept there up to 22 days post exposure (dpe). The same procedure was applied for control group mosquitoes, where a non-infected siskin was used to feed the females obtained from the main colony. Experimental mosquitoes were dissected gradually for preparations of different sporogonic stages. For ookinete preparations mosquitoes were dissected 1-3 dpe, for 
oocysts 8-22 dpe and for sporozoite preparations 12-22 dpe. Before dissection, all insects were euthanized in an entomological aspirator with cottonwool moistened with 96\% ethanol. The preparations of all sporogony stages were made according Žiegytè et al. [30].

In total, $26 C x$. pipiens form molestus and $26 C x$. quinquefasciatus mosquitoes were engorged. In the control group, $25 \mathrm{Cx}$. pipiens form molestus had uninfected blood meals.

\section{Microscopic examination of blood smears and species identification}

For blood smears screening, examination of sporogonic stages and parasitaemia calculation in experimental individuals an Olympus $\mathrm{CH} 2 \mathrm{O}$ light microscope with $\times 40$ and $\times 100$ magnifications was used. Pictures for measurements of the parasite at its different blood stages were prepared by using the Olympus BX61 light microscope equipped with digital camera DP70. Visualization of pictures was performed using the software AnalySIS FIVE (Olympus Soft Imaging Solutions GmbH, Münster, Germany). Blood smears obtained from wild birds were examined about $15-20$ min with $\times 100$ magnification. To evaluate the intensity of parasitaemia, numbers of infected erythrocytes per 10,000 red blood cells were counted $[28,31]$.

\section{Molecular examination and phylogenetic analysis}

Total DNA was extracted from whole blood stored in SET-buffer, using the ammonium-acetate protocol [32]. The standard nested PCR protocol was used to amplify $478 \mathrm{bp}$ fragment of the mitochondrial cytochrome $b$ gene (cyt $b$ ) of $P$. collidatum [33, 34]. To control for a false amplification one positive control (DNA of $P$. relictum pSGS1) and one negative control (nuclease-free water) were used every10 samples. Final PCR-products were checked for the success of amplification by running them on $2 \%$ agarose gel. Obtained fragments were sequenced from both $5^{\prime}$ and $3^{\prime}$ ends using an ABI PRISM TM 3100 capillary sequencing robot (Applied Biosystems, USA). Obtained sequences were aligned in BioEdit software [35] and identified using BLAST-program of GenBank [36] and MalAvi database [17].

Phylogenetic analysis of the pFANTAIL01 with 28 additional sequences of haemosporidian parasites was conducted using the Bayesian method and performed in MrBayes v.3.1 [37]. The General Time Reversible Model with a proportion of invariable sites and variation among sites $(\mathrm{GTR}+\mathrm{I}+\mathrm{G})$ was selected by the mrModeltest 3.7 program [38] as the best fitting model. In total, 3 million generations were run with a sample frequency of every 100th generation. Twenty five percent of obtained trees representing the burn-in phase were discarded.
Remaining trees were used for the determination of the consensus tree. The final phylogenetic tree was visualized using FigTree software 1.4.4. [39]. The sequence divergence between different lineages was calculated by applying the Jukes-Cantor model of substitution implemented in the program MEGA 6.0 [40].

\section{Statistical analysis}

The statistical analysis was performed by using the RStudio interface based on R software [41]. The normality of distribution in the experimental dataset was evaluated by employing the Shapiro-Wilk test. Wilcoxon rank-sum test was used for the analysis of differences in haematocrit and body mass values between experimental and control groups of siskins. P-value above or equal to 0.05 was considered as significant.

\section{Results}

Description of parasite

Plasmodium (Novyella) collidatum n. sp.

DNA-sequence Mitochondrial cyt $b$ lineage pFANTAIL01 (478 bp, GenBank accession no. MW175901).

Type host The Common rosefinch Ca. erythrinus (Passeriformes, Fringillidae).

Additional hosts According to literature data the lineage pFANTAIL01 (synonym codes AP63, GenBank accession no. AY714196; C028, DQ212193 and ASI-2012, JX418225) have been recorded in 18 species of 15 families in 7 orders of naturally infected birds (see Table 1). Eurasian siskin was susceptible to experimental infection and could be a competent host.

Type locality The Curonian Spit of the Baltic Sea $\left(55^{\circ} 09^{\prime} 14 \mathrm{~N}, 20^{\circ} 51^{\prime} 27 \mathrm{E}\right)$.

Prevalence 71 Common rosefinches were collected and examined for haemosporidian infection on Curonian spit in 2010-2019 years. About $7 \%$ of all rosefinches were infected with different species of blood parasites. $P$. collidatum was reported in one bird individual in 2019. According to MalAvi database, this lineage is rare in Europe.

Site of infection Erythrocytic meronts and gametocytes developed in mature red blood cells (Fig. 1); no other data.

Vectors Natural vectors are unknown. Mosquitoes of $C x$. pipiens form molestus and Cx. quinquefasciatus were not susceptible to $P$. collidatum. 
Table 1 Host range and distribution of Plasmodium collidatum n. sp. (lineage pFANTAIL01) based on molecular examination (places in Results/Description of parasite chapter)

\begin{tabular}{|c|c|c|c|}
\hline Order and family of the avian host & Species of the avian host & Locality & Reference \\
\hline \multicolumn{4}{|l|}{ Anseriformes } \\
\hline Anatidae & Dendrocygna javanica & Unknown & {$[42]$} \\
\hline \multicolumn{4}{|l|}{ Bucerotiformes } \\
\hline Bucerotidae & Penelopides panini & Philippines & [43] \\
\hline \multicolumn{4}{|l|}{ Charadriiformes } \\
\hline Scolopacidae & Calidris tenuirostris & Australia & {$[44]$} \\
\hline \multicolumn{4}{|l|}{ Falconiformes } \\
\hline Accipitridae & Milvus sp. & Spain & {$[45]$} \\
\hline \multicolumn{4}{|l|}{ Passeriformes } \\
\hline Acanthizidae & Sericornis magnirostris & Australia & {$[46]$} \\
\hline Fringillidae & Carpodacus erythrinus & Czech Republic & {$[18]$} \\
\hline \multirow[t]{2}{*}{ Maluridae } & Malurus coronatus & Australia & {$[47]$} \\
\hline & Malurus melanocephalus & Australia & [47] \\
\hline Pachycephalidae & Pachycephala simplex & Australia & {$[46]$} \\
\hline Petroicidae & Poecilodryas albispecularis & Australia & {$[46]$} \\
\hline Rhipiduridae & Rhipidura rufifrons & Australia & [42] \\
\hline \multirow[t]{2}{*}{ Sturnidae } & Acridotheres tristis & Singapore, Australia & {$[48,49]$} \\
\hline & Pastor roseus & Bulgaria & {$[50]$} \\
\hline Turdidae & Turdus merula & India & {$[51]$} \\
\hline Zosteropidae & Zosterops lateralis & Australia & {$[49,52]$} \\
\hline \multicolumn{4}{|l|}{ Psittaciformes } \\
\hline \multirow[t]{2}{*}{ Cacatuidae } & Calyptorhynchus funereus & Australia & {$[53]$} \\
\hline & Calyptorhynchus lathami & Australia & {$[53]$} \\
\hline \multicolumn{4}{|l|}{ Strigiformes } \\
\hline Strigidae & Glaucidium cuculoides & Thailand & {$[54]$} \\
\hline
\end{tabular}

Distribution According to the molecular data, P. collidatum pFANTAIL01 has been reported in South Asia, SE Asia, Australia, and neighbouring islands as well as in Europe (Table 1). In South Asia, SE Asia and Australia, $P$. collidatum has been found in numerous species of resident and migratory birds. Among infected European birds in the temperate zone, this lineage was confirmed only in adult birds of those species which are wintering in South Asia (Ca. erythrinus, Pastor roseus).

Type specimens Hapantotype (accession nos. 49,24249,244 NS, intensity of parasitaemia is approximately $0.3 \%$, Ca. erythrinus, the Curonian spit, Kaliningrad district, Russia, $36^{\circ} 44^{\prime} \mathrm{N}, 119^{\circ} 29^{\prime} \mathrm{W}$, collected 6 June 2019 by E. Platonova) is deposited in the Nature
Research Centre, Vilnius, Lithuania. Parahapantotypes (accession nos. G466222, G466223 [1149b/19C, $1220 \mathrm{~b} / 19 \mathrm{C}])$, the intensity of parasitaemia is approximately $10 \%$ and $3.3 \%$ respectively, of experimentally infected Cr. spinus, collected 26-30 July 2019 by E. Platonova) are deposited in the Queensland Museum, Queensland, Australia.

Additional material Blood films from experimentally infected Cr. spinus (accession nos. 1149/19C, 1219/19c, 1220/19C, 1367/19C) and blood samples fixed in SETbuffer (accession nos. 1149/19C, 1219/19c, 1220/19C, 1367/19C) are deposited in the Nature Research Centre, Vilnius, Lithuania.

(See figure on next page.)

Fig. 1 Plasmodium collidatum n. sp. (lineage pFANTAIL01) from the blood of the Common rosefinch Carpodacus erythrinus: a, b trophozoites, $\mathbf{c}-\mathbf{j}$ - erythrocytic meronts, $\mathbf{k}-\mathbf{y}$-macrogametocytes, $\mathbf{z}-\mathrm{dd}$-microgametocytes. Long simple arrows—clumps of chromatin; short simple arrows_cytoplasm in meront; triangle heads_-pigment granules; simple wide heads—vacuole-like spaces; short simple wide arrows_cytoplasm in merozoites. Giemsa-stained thin blood films. Scale bar $=10 \mu \mathrm{m}$ 


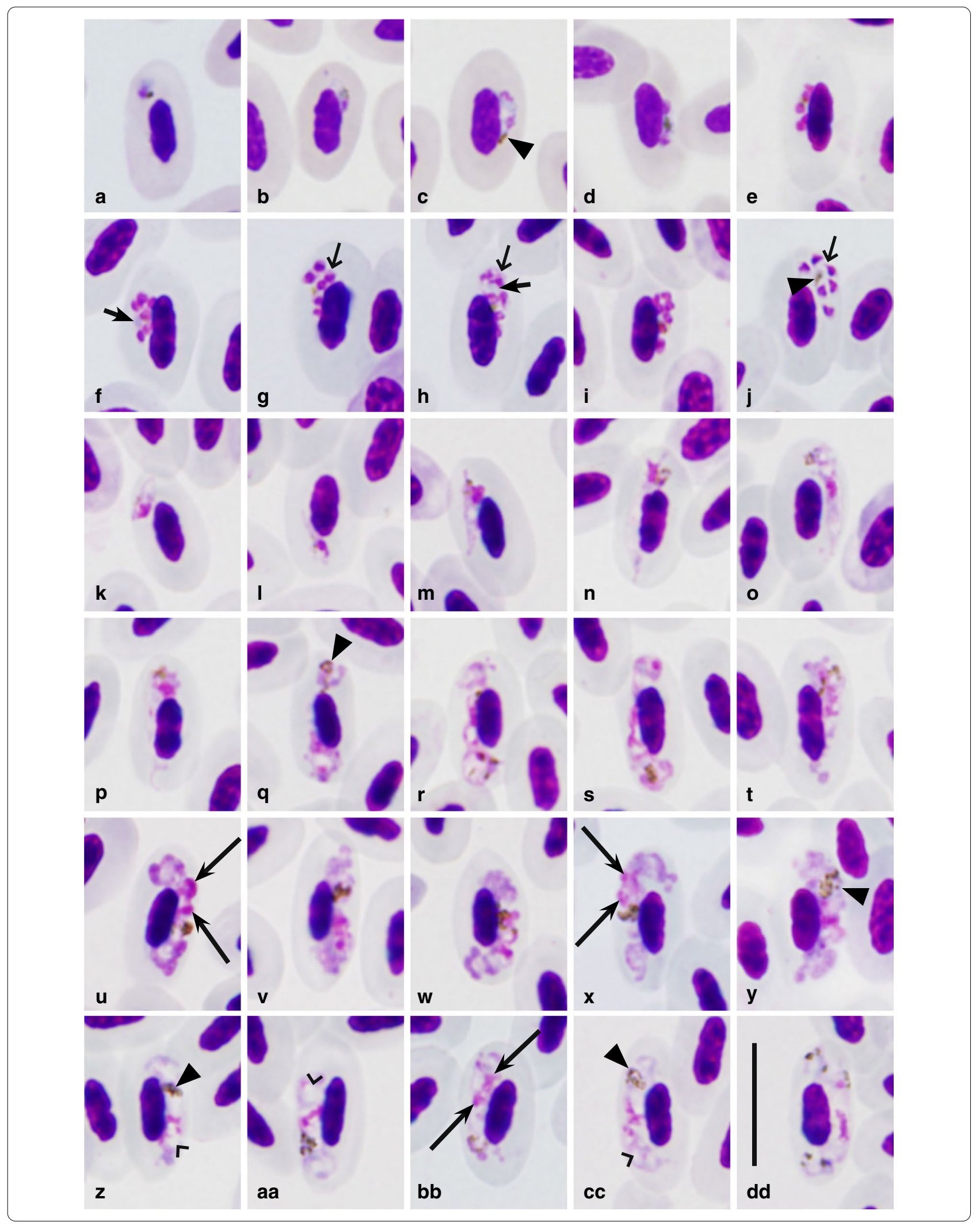


Etymology The specific name reflects the morphological feature-markedly indented (lobular-like) appearance of the pellicle, which is typical for advanced gametocytes.

Exoerythrocytic meronts Primary exoerythrocytic merogony (cryptozoites and metacryptozoites) was not investigated and remain unknown. Numerous secondary exoerythrocytic meronts (phanerozoites) were found in the lungs (Fig. 2a-c) of the infected individuals and appeared elongated (Fig. 2a), oval (Fig. 2b) or irregularly shaped (Fig. 2c). Phanerozoites in the lungs contained over 30 roundish merozoites. In smaller numbers, phanerozoites were also seen in the liver (Fig. $2 d-f$ ), spleen (Fig. 2g-i) and kidneys (Fig. 2j-l) of the infected individuals. In these organs phanerozoites appeared roundish or slightly oval and contained less than 30 merozoites.

Trophozoites (Fig. 1a, b) are most often seen in mature erythrocytes, however, rarely can be observed in polychromatophilic red blood cells. Round or oval trophozoites are located at the poles of infected erythrocytes. As trophozoites mature, they attach to the nucleus of the infected erythrocyte and this contact is maintained.

Erythrocytic meronts (Fig. 1c-j; Table 2) found only in mature erythrocytes. Growing meronts contain little, but readily visible, blue in colour cytoplasm and small pigment granules (Fig. 1c); in mature meronts cytoplasm is rarely seen. Both, in growing and mature meronts a small bluish roundish and non-refractive globule is often seen (Fig. 1f, h). Meront with developing merozoites touches the erythrocyte nucleus, located laterally or close to the pole of the infected cell and this contact is maintained during the whole time of maturation (Fig. 1c-i). Grown meronts are oval or irregularly shaped and contain 4-8 merozoites (Fig. 1e-i). Pigment granules in mature meronts are small and clumped, however, scattered granules can also be seen in some cells (Fig. 1j). Effect of the gametocyte on the infected erythrocyte is not expressed. Mature merozoites contain prominent irregular-shaped nuclei, and each contains a small portion of readily visible cytoplasm (Fig. 1g, j).

Macrogametocytes (Fig. 1k-y; Table 2) found only in mature erythrocytes. The cytoplasm is markedly heterogeneous and is unevenly stained: more dense stained portions of the cytoplasm are intermediated with pale stained portions, which look like large vacuole-like palestained spaces (Fig. 1q-s, w, y), a characteristic feature of this species. Young forms usually found in the poles of infected erythrocytes. In the earliest growing gametocytes, long outgrowths often appear (Fig. 11). Gametocytes vary in outline from amoeboid in growing to wavy in mature parasites. Gametocytes are located laterally to the nucleus of the infected erythrocyte; maturing and mature gametocytes are strictly nucleophilic, however, growing forms not touching the nucleus can also be seen occasionally (Fig. 10). A central part of the pellicle of some growing gametocytes does not extend to erythrocyte envelope causing a 'dip', which gives dumbbell-shaped form (Fig. 1q, r). Typically, the growing gametocytes are asymmetric in appearance, with one end being broader than the other one (Fig. 1p, s, t, x). Fullygrown gametocytes often do not adhere to the envelope of the erythrocyte and do not fill the poles of erythrocytes (Fig. 1x, y). Markedly wavy lobular-like appearance of the pellicle (on the opposite side to erythrocytes nucleus) of mature gametocytes is an important distinctive feature of this species (Fig. 1u, w). The cytoplasm stains more densely in lobules than in indented areas. The nucleus of the gametocyte is diffused and of unclear outline; it consists of several chromatin clumps, which visually look to be non-connected with each other in Giemsa-stained preparation and can be seen closer to center or anywhere in the gametocyte, a characteristic feature of this species (Fig. 1s-y). Due to the pale cytoplasm staining and diffuse nucleus, macrogametocytes are difficult to distinguish from microgametocytes. Pigment granules are roundish, of small $\left({ }^{<} 0.5 \mu \mathrm{m}\right)$ size, most often grouped in one relatively large distinct spot, but occasionally also were seen scattered in the cytoplasm (Fig. 1s-x). The area of the pigment granule groups is relatively large, and this feature attracts attention during microscopic examination (Fig. 1y). Individual pigment granules do not change size and shape during the development of gametocytes, a rare feature in avian malaria parasites. Effect of the gametocyte on the infected erythrocyte is not expressed.

Microgametocyte (Fig. 1z-dd; Table 2) are difficult to distinguish from the macrogametocytes based on the intensity of the cytoplasm staining and appearance of parasite nuclei. The cytoplasm is relatively paler in the microgametocytes, all other characters are as in macrogametocytes. In the blood of type host, microgametocytes were seen extremely rare, and this prevented the complete picture of the morphometry of parasite.

\section{Taxonomic summary}

Morphology of $P$. collidatum-small meronts, a small amount of cytoplasm in meronts and elongated shape of grown gametocytes allows linking this species with the subgenus Novyella. Nucleophilic stages developing in the blood of the infected host allows to discriminate this species from other non-nucleophilic species of Novyella.This parasite can be readily distinguished from all nucleophilic Novyella species due to the following morphological characteristic of its mature gametocytes: (i) the cytoplasm consists of intermediated readily visible large pale-stained and dense-stained areas, providing 

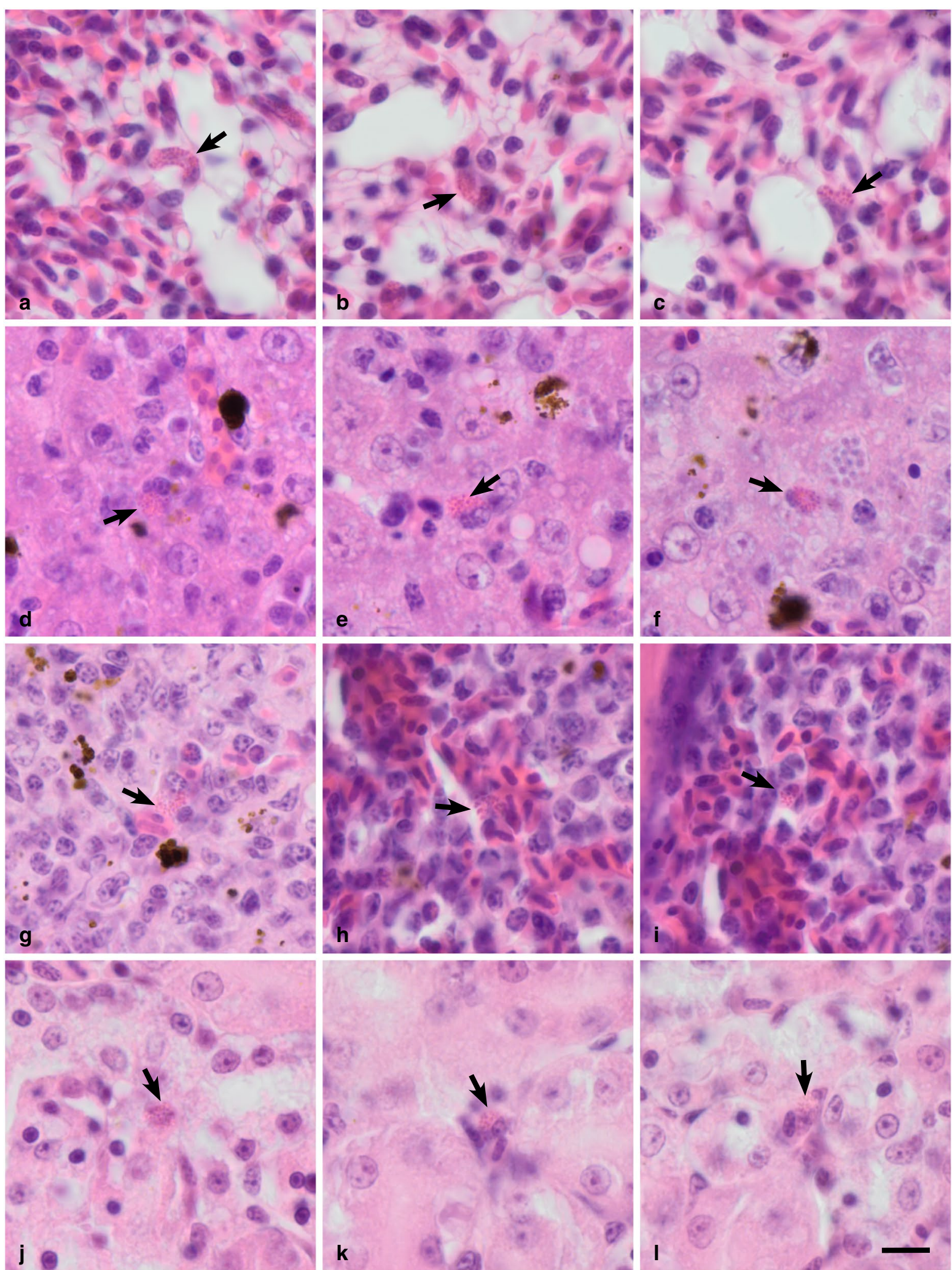

Fig. 2 Phanerozoites of Plasmodium collidatum n. sp. (lineage pFANTAIL01) from a naturally infected Common rosefinch Carpodacus erythrinus in: a-c —lung, d-f-liver, $\mathbf{g}-\mathbf{i}$-spleen, $\mathbf{j}$ - - — kidney. Arrows indicate the phanerozoites. Haematoxylin and eosin-stained histological sections. Scale bar $=10 \mu \mathrm{m}$ 
Table 2 Morphometry of host cells, mature gametocytes and erythrocytic meronts of Plasmodium collidatum $\mathbf{n}$. sp. (lineage pFANTAIL01) $(n=21)$ (places in Results/Description of parasite chapter)

\begin{tabular}{|c|c|}
\hline Feature & Measurements $(\mu \mathrm{m})^{a}$ \\
\hline \multicolumn{2}{|l|}{ Uninfected erythrocyte } \\
\hline Length & $10.4-12.4(11.5 \pm 0.5)$ \\
\hline Width & $6.1-7.2(6.5 \pm 0.3)$ \\
\hline Area & $52.8-67.8(60.5 \pm 4.3)$ \\
\hline \multicolumn{2}{|c|}{ Uninfected erythrocyte nucleus } \\
\hline Length & $5.1-6.2(5.5 \pm 0.3)$ \\
\hline Width & $2.1-2.8(2.3 \pm 0.2)$ \\
\hline Area & $9.5-14.8(10.8 \pm 1.1)$ \\
\hline \multicolumn{2}{|l|}{ Macrogametocyte } \\
\hline \multicolumn{2}{|l|}{ Infected erythrocyte } \\
\hline Length & $11.2-13.6(12.4 \pm 0.6)$ \\
\hline Width & $5.3-7.38(6.1 \pm 0.5)$ \\
\hline Area & $52.4-71.5(60.4 \pm 4.7)$ \\
\hline \multicolumn{2}{|c|}{ Infected erythrocyte nucleus } \\
\hline Length & $4.6-5.8(5.2 \pm 0.3)$ \\
\hline Width & $1.6-2.5(2.1 \pm 0.2)$ \\
\hline Area & $7.0-10.8(9.0 \pm 1.1)$ \\
\hline \multicolumn{2}{|l|}{ Gametocyte } \\
\hline Length & $9.6-13.2(11.5 \pm 1.1)$ \\
\hline Width & $0.9-2.5(1.5 \pm 0.4)$ \\
\hline Area & $18.2-28.9(21.8 \pm 2.6)$ \\
\hline \multicolumn{2}{|l|}{ Gametocyte nucleus } \\
\hline Length & - \\
\hline Width & - \\
\hline Area & - \\
\hline Pigment granules & $7.0-14.0(8.2 \pm 1.7)$ \\
\hline \multicolumn{2}{|l|}{ Microgametocyte $(n=6)$} \\
\hline \multicolumn{2}{|l|}{ Infected erythrocyte } \\
\hline Length & $10.7-14.1(12.3 \pm 1.3)$ \\
\hline Width & $6.0-6.6(6.2 \pm 0.2)$ \\
\hline Area & $53.0-70.5(61.6 \pm 7.3)$ \\
\hline \multicolumn{2}{|c|}{ Infected erythrocyte nucleus } \\
\hline Length & $4.9-5.8(5.3 \pm 0.4)$ \\
\hline Width & $2.0-2.6(2.2 \pm 0.2)$ \\
\hline Area & $9.1-10.6(9.9 \pm 0.6)$ \\
\hline \multicolumn{2}{|l|}{ Gametocyte } \\
\hline Length & $10.5-13.0(12.2 \pm 1.0)$ \\
\hline Width & $1.8-2.3(2.0 \pm 0.2)$ \\
\hline Area & $17.5-25.5(21.6 \pm 3.0)$ \\
\hline \multicolumn{2}{|l|}{ Gametocyte nucleus } \\
\hline Length & $1.3-3.8(2.8 \pm 1.0)$ \\
\hline Width & $0.5-0.7(0.6 \pm 0.1)$ \\
\hline Area & $0.9-1.2(1.0 \pm 0.2)$ \\
\hline Pigment granules & $-b$ \\
\hline \multicolumn{2}{|l|}{ Meront } \\
\hline Length & $2.8-5.6(4.4 \pm 0.7)$ \\
\hline Width & $1.0-2.2(1.7 \pm 0.3)$ \\
\hline Area & $3.7-8.0(5.5 \pm 1.3)$ \\
\hline No. of pigment granules & $-{ }^{b}$ \\
\hline No. of merozoites & $4.0-8.0(5.8 \pm 1.2)$ \\
\hline
\end{tabular}

Table 2 (continued)

a Minimum and maximum values are provided, followed in parentheses by the arithmetic mean and standard deviation

b Pigment granules are clamped and are difficult to calculate

markedly heterogeneous appearance, (ii) the majority of advanced gametocytes possesses the markedly indented (lobular-like) appearance of pellicle and (iii) macro- and microgametocytes are difficult to distinguish based on their size and morphology of their nuclei. Additionally, the presence of a relatively large loose group on small pigment granules is also helpful during this parasite identification (see our description and [12, 13, 55-57]). The described parasite morphologically is the most similar to $P$. delichoni however, some features, like small roundish granules clearly distinguish this parasite from $P$. delichoni. Other mentioned nucleophilic species also have additional features, which are not found in the described parasite. Growing meronts of Plasmodium nucleophilum often displace the nuclei of the infected erythrocytes and its macrogametocytes have a compact nucleus; Plasmodium paranucleophilum possesses gametocytes, which push the nucleus in infected erythrocyte laterally; gametocytes of $P$. homonucleophilum are not strictly nucleophilic. None of the above-mentioned features is characteristics of the newly described species. The main morphological features of described parasite blood stages, which were observed in type host (Ca. erythrinus) also maintained in Eurasian siskins after experimental infection. Very occasionally meronts with 9 and 10 merozoites appeared in experimentally infected siskins, but not in type host.

\section{Phylogenetic analysis}

According to the phylogenetic analysis, the lineage pFANTAIL01 clusters together with $P$. nucleophilum lineage pDENPET03 (Fig. 3). The genetic distance between these two lineages is $4.31 \%$. Both lineages cluster within a bigger clade with other two Novyella parasites e.g. P. ashfordi (pGRW2) and P. delichoni (pCOLL6). However, the genetic difference between pFANTAIL01 and the latter two cyt $b$ lineages is 8.43 and $10.45 \%$, respectively. Plasmodium collidatum (pFANTAIL01) morphologically is the most similar to pCOLL6, but distribution and host range of these lineages differ.

\section{Development and caused virulence in experimentally infected birds}

All experimentally exposed siskins were susceptible to P. collidatum (pFANTAIL01) and showed the complete development of all blood stages of the parasite. Both PCR 


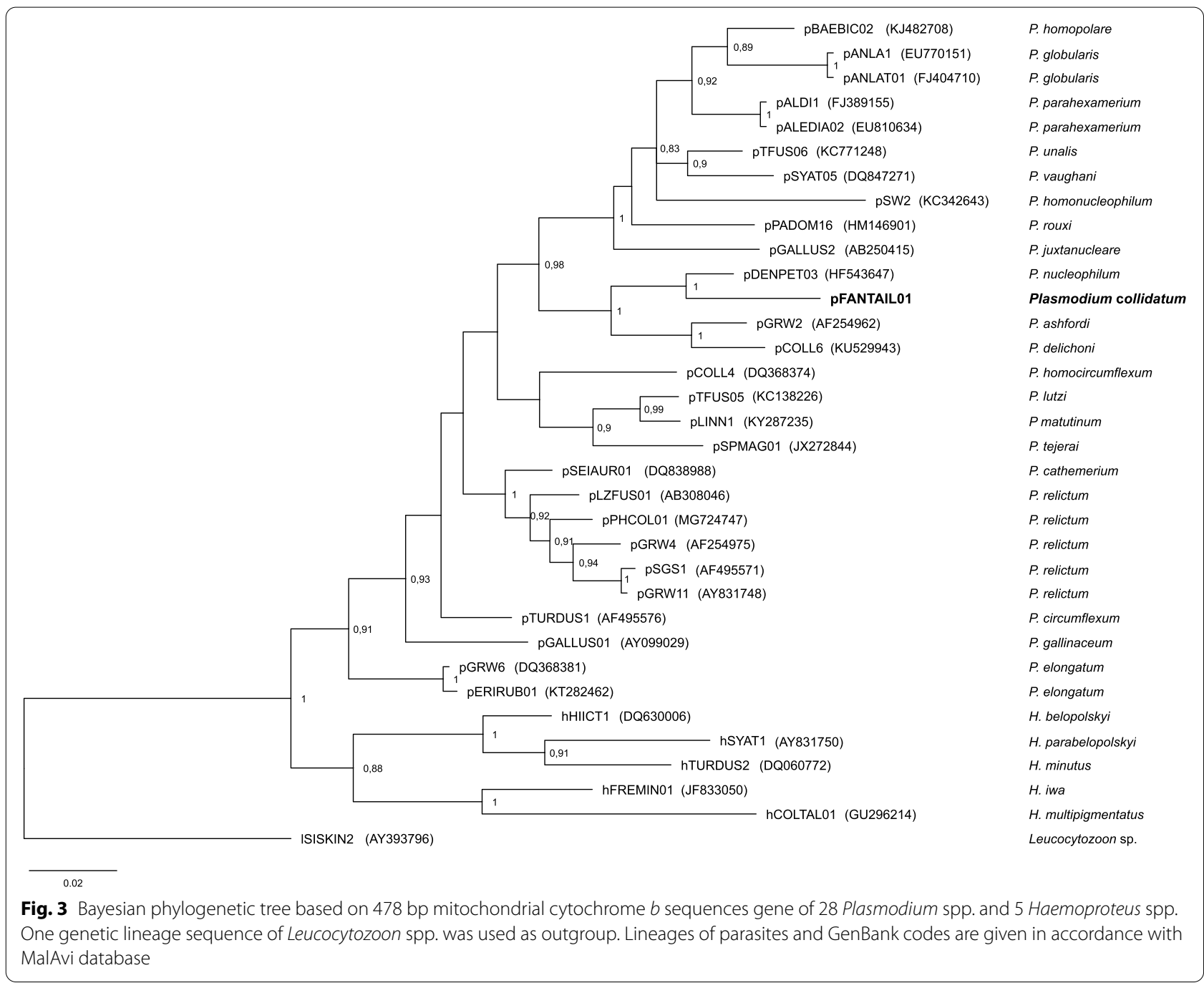

and microscopic examination showed that all controls remained uninfected until the end of the experiment.

Prepatent period of infection, when the first infected erythrocytes were detected in the blood smears varied between 12 and 20 days post infection (dpi), (Fig. 4). Dynamics of parasitaemia were highly variable between individuals (Fig. 4); in some reaching up to $70-80 \%$, while in others only $<1 \%$. In half of infected birds after sharp increase of parasitaemia, there was typical bell-shaped form of primary parasitaemia with clearly decreasing slope after the sharp initial increase. High parasitaemia maintained in most of the experimental birds up to 36 dpi, reaching up to $11-75 \%$ (Figs. 4 and 5). Two birds died with parasitaemias of 15 and $18 \%$ on $32 \mathrm{dpi}$. All control birds survived until the end of the experiment.

The average body mass of the infected birds did not differ significantly from the control group throughout the experiment $(\mathrm{W}=4415$, $\mathrm{p}$-value $=0.6502$, Fig. 6a). The mean haematocrit value was decreasing gradually

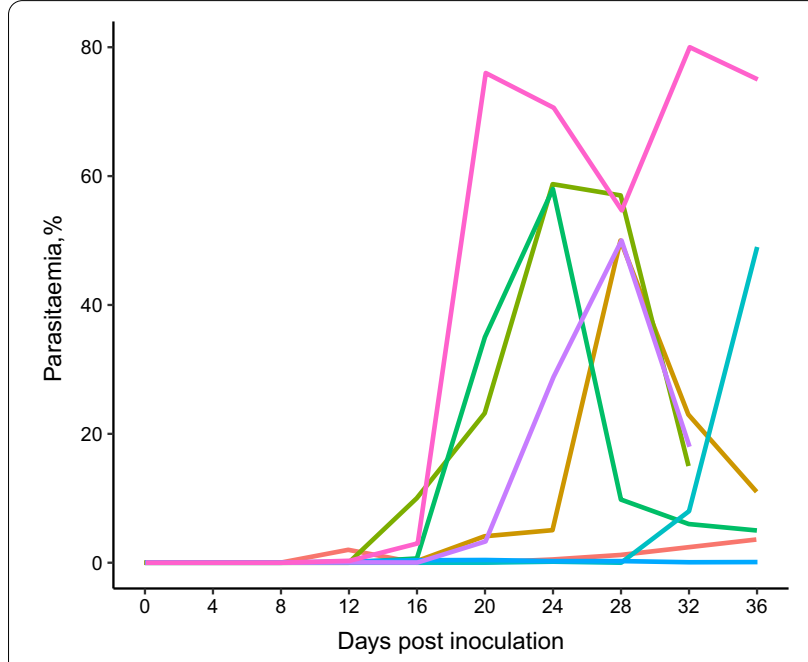

Fig. 4 Individual development of parasitaemia of Plasmodium collidatum n. sp. (pFANTAIL01) in experimentally infected siskins 


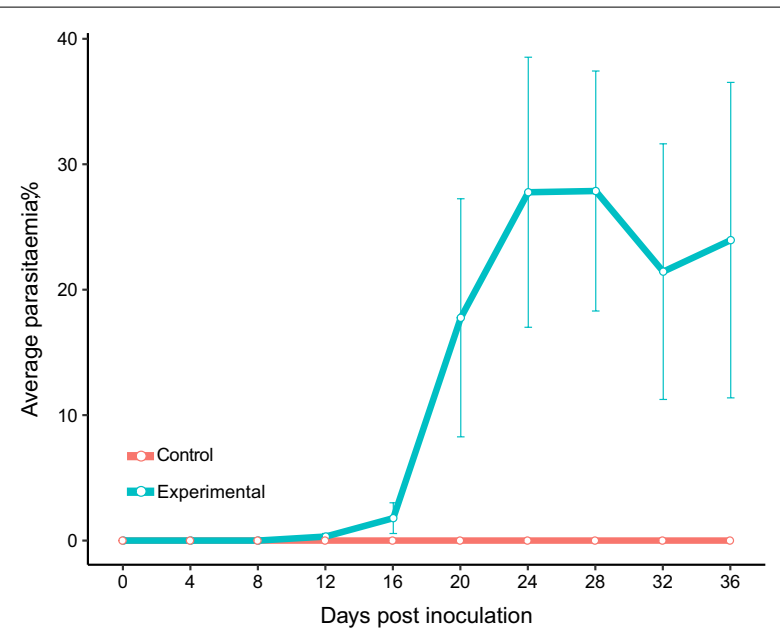

Fig. 5 Dynamic of mean parasitaemia of Plasmodium collidatum (pFANTAIL01) in experimentally infected siskins. Vertical lines indicate standard error

during the experiment in infected birds, however, there were no significant differences between infected and control siskins $(\mathrm{W}=4427, \mathrm{p}$-value $=0.4631$; Fig. $6 \mathrm{~b})$. The biggest, but not significant difference between two groups was $32 \mathrm{dpi}(\mathrm{W}=53$, $\mathrm{p}$-value $=0.08689)$.

\section{Development in experimentally infected mosquitoes}

After screening $C x$. pipiens form molestus and $C x$. quinquefasciatus midguts and salivary glands preparations it was determined that ookinetes, oocysts and sporozoites in all exposed to $P$. collidatum (pFANTAIL01) mosquitoes within 22 days after blood feeding were absent. Authors also did not detect any zygotes within $48 \mathrm{~h}$ in preparations of mosquito midgut contents.

\section{Discussion}

pFANTAIL01 lineage from the Common rosefinch was identified as Plasmodium (Novyella) collidatum n. sp. The morphological analysis of the erythrocytic stages of the parasite showed that $P$. collidatum has typical features associated with Novyella subgenus: elongated gametocytes, small meronts and parasitizing only in mature red blood cells [4]. Based on several unique morphological features of blood stages of pFANTAIL01 lineage it is possible to distinguish it from other Novyella parasites and to define this parasite as a separate species (see "Taxonomic summary").

Analysis of accumulated molecular data shows that $P$. collidatum has been recorded predominantly in Oceania and SE Asia (Table 1). It was recorded not only in migrant, but also in resident bird species. The transmission, apparently, takes place in these regions. Several records of pFANTAIL01 were reported in bird species breeding in Europe, Common rosefinch [18], Rosy starling [50] and in one of Milvus sp. [45]. All above mentioned passerines were adults after their spring migration returning from South Asia, therefore, it is highly probable that transmission of this parasite does not occur in Europe.

Interestingly, there is one case of $P$. collidatum in Spain, from a bird of Milvus genus [45]. There might be two species of Milvus in Europe, one is M. milvus and the second one, $M$. migrans but European populations of both these species do not migrate to South or SE Asia [45]. However, as this is a single record in a raptor bird, it is difficult to
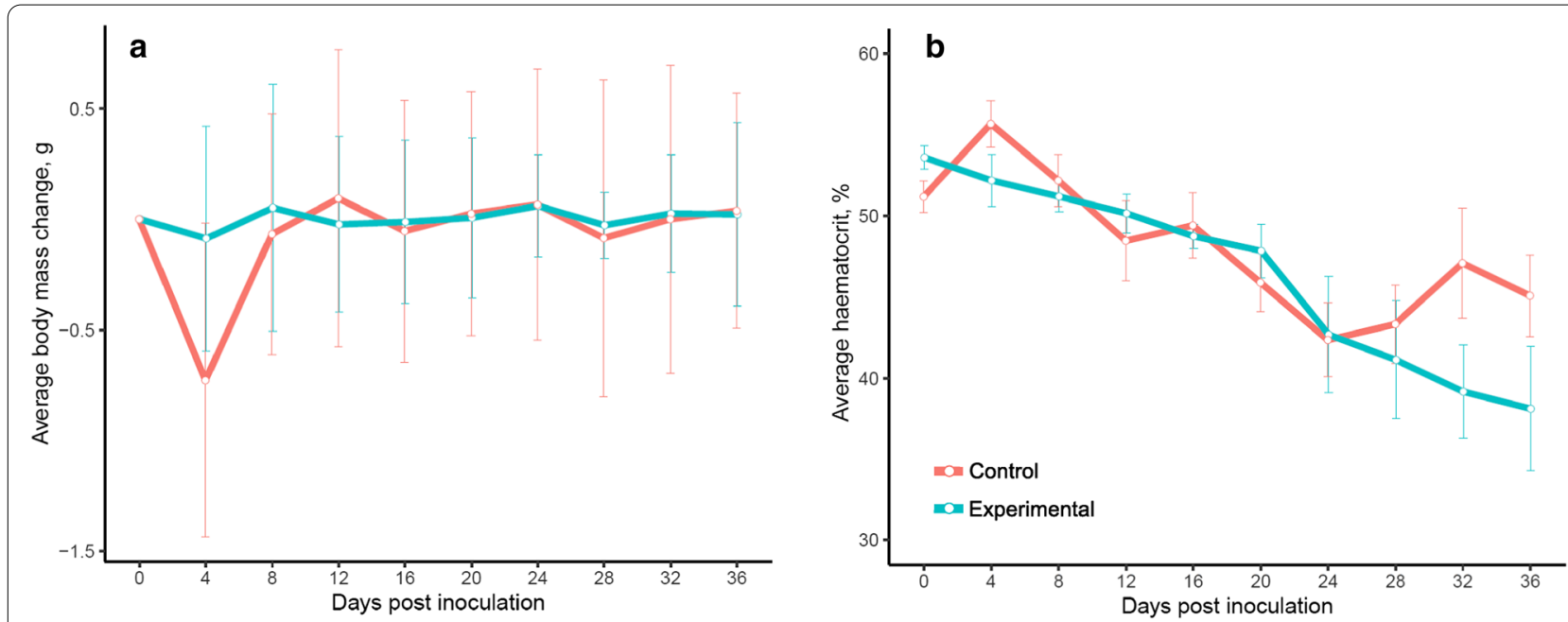

Fig. 6 Dynamic of body mass (a) and haematocrit (b) in experimentally infected and control birds. Vertical lines indicate standard error 
make a definite conclusion where and how the bird was infected [58].

According to the MalAvi and GenBank databases, pFANTAIL01 lineage has been reported in wide range of birds of 17 species, 14 families and 7 orders prevailing, herewith, in Passeriformes (Table 1). Apparently, $P$. colllidatum is of low specificity for the vertebrate host and, therefore, can be considered as a generalist species. Although, it is unclear if $P$. collidatum develops gametocytes in all of the mentioned species as the presence of infection in blood was confirmed only by molecular methods and the possibility of abortive parasite development could not be excluded $[9,59]$.

The damage caused by malaria parasites can be by the tissue stages of exoerythrocytic merogony or by the pathogenic effect due to severe anaemia caused by erythrocytic stages of the parasite $[10,60]$. The pathogenic effect of the exoerythrocytic meronts was described in bird species of different families and orders $[4,6,60]$ but development and pathogenicity of tissue stages in genera Novyella is poorly studied [12,61]. Phanerozoites were described in P. nucleophilum toucani with huge infestation of internal organs and caused mortality in experimentally infected canaries [62]. Phanerozoites were also seen in different internal organs of birds infected by $P$. vaughani [4], P. paranucleophilum [57] and Plasmodium bertii [4].

The pathogenic effect of the exoerythrocytic stages of $P$. collidatum was reported only in two species of cockatoo, a Yellow-tailed black cockatoo Calyptorhynchus funereus and Glossy black cockatoo Calyptorhynchus lathami [53]. Both birds were infected in captivity and died despite of the medical treatment. The histological analysis showed a large infestation of schizonts in their liver, spleen, lungs and intestines together with hemorrhage and necrosis of other tissues [53]. Birds died, apparently, due to the extensive damage of their internal organs by the tissue stages of $P$. collidatum. According to the authors, these Australian species live in habitats where the presence of potential vectors is restricted. Both housing cockatoo birds were kept not in their species-specific conditions thus they most likely were exposed to parasite vectors. In the present experiment, numerous phanerozoites were observed in liver, lungs, spleen and kidney tissue of infected siskins. Two of eight birds died at the end of study after decreasing of parasitaemia.

Two mutually non-exclusive factors, the depleted immune system and pathologies caused by phanerozoites could trigger the death of the host. Similar cases have been reported by Ilgūnas et al. [63] in experimentally infected crossbill (Loxia curvirostra), siskin and starling (Sturnus vulgaris) which were inoculated with a highly virulent parasite $P$. (Giovannolaia) homocircumflexum (lineage pCOLL4) and mortalities of birds were observed after the peak of parasitaemia.

The negative impact of erythrocytic stages of Plasmodium is most noticeable when the parasite damages a big number of blood cells $[28,64-66]$. The limited information about the development of Novyella parasites is obtained up to now comparing to some Haemamoeba or Giovannolaia species. It was considered that Novyella parasites are mainly of low virulence to birds [67]. However, the studies with infection of tropical origin, $P$. ashfordi (pGRW2) and P. delichoni (pCOLL6) showed that these Novyella parasites develop high intensities of parasitaemia in experimental birds [12, 15, 68, 69]. According to the present study, siskins are susceptible to $P$. collidatum. The prepatent period varied between individuals but was relatively long in all experimental birds (Fig. 4). This data is in consistent manner with the information about the development of other species of Novyella e.g. P. vaughani where the prepatent period lasts from 1 to 6 weeks [4, 70], in P. ashfordi-2-4 weeks [15], in $P$. delichoni-2-3 weeks [12]. The dynamic of parasitaemia varied among individuals reaching peak values up to $0.42-80 \%$ (Fig. 4), but was rather extended in time comparing to other species from the most studied parasites from subgenus Haemamoeba which characterized by rapid increase of parasitaemia and rapid decrease to chronic values within $36 \mathrm{dpi}[28,71]$.

During the study, the impact of $P$. collidatum on body mass and haematocrit level of infected birds was measured (Fig. 6a, b). The negative effect on body mass of the infected siskins was not detected (Fig. 6a). This data agrees with former experimental studies where even severe malaria infection did not affect the body mass of infected individuals, probably, because birds kept in laboratory conditions were receiving food ad libitum and were able to compensate the energy loss $[10,28,72]$. Haematocrit level slightly decreased in infected birds on $32 \mathrm{dpi}$, but the difference between infected and control birds was insignificant (Fig. 6b). This is not a typical case for parasites from other subgenera, because the increase of parasitaemia usually causes the decrease in the number of RBCs $[6,28,73]$. During the infection with Haemamoeba parasite $P$. relictum (pSGS1), the quick raise of parasitaemia is immediately followed by a sharp drop of haematocrit value [28]. On the other hand, Palinauskas et al. [9] showed that single infection with low parasitaemia (less than $1 \%$ ) by Huffia subgenus parasite P. elongatum (pERIRUB01) dramatically decreased the haematocrit value in experimentally infected siskins. The similar situation was observed in canaries infected with Novyella species P. paranucleophilum, the bone marrow of infected birds had heavy invasion at low parasitaemia but anemia was clearly manifested by the 
decrease in haematocrit values [57]. Apparently, a huge infestation of bone marrow by phanerozoites reduces erythropoiesis and, therefore, decrease haematocrit values. At the present study, the exoerythrocytic stages in the bone marrow of the infected siskins were not detected. Probably, the erythropoietic system was compensating the loss of erythrocytes until its depletion on 32 dpi when slight decrease of haematocrit in infected birds but further experimental studies are needed to clarify this point.

The annual migration of birds is an important factor for a possible invasion of new haemosporidian species $[4,74]$. However, to complete the life cycle on new territories parasites need a competent vector (Culicidae mosquitoes) and suitable environmental conditions. At the present study, $C x$. pipiens form molestus and $C x$. quinquefasciatus were used for the experimental investigations. Culex pipiens form molestus is the common mosquito species distributed around the world and was confirmed as a natural and potential vector for a number of Plasmodium species [9, 24, 30, 75, 76]. Culex quinquefasciatus is more distributed in subtropical and tropical regions and is known to transmit avian malaria parasites as well $[77,78]$. However, mosquitoes of both species experimentally exposed to infection of $P$. collidatum were not susceptible to this parasite. Neither ookinetes, oocysts or sporozoites were detected in any of the exposed insects. Also, zygotes were not seen in blood smears from engorged mosquitoes. Apparently, sporogonic development was aborted on the stage of forming gametes. Further studies are needed to identify a competent vector species for this parasite.

Knowledge about natural vectors of pathogens causing lethal diseases is a cornerstone for the basic understanding of epizootiology of any disease and possible threats in the future. The introduction of competent vector species could lead to the establishment of the tropical P. collidatum (pFANTAIL01) in Europe and that could further lead to an outbreak of new malarial infection in local birds which did not co-evolve with the introduced parasite. In the present study, it was experimentally demonstrated that susceptible avian species which could enhance the transmission of tropical pathogen exist in Northern Palearctic.

Despite the fact, that $P$. collidatum did not develop in $C x$. pipiens form molestus, there are other mosquitoes, especially invasive species, which potentially, could serve as a vectors of this parasite. The anthropogenic activity and the global warming are the main factors contributing to the increased numbers of invasive species of mosquitoes and other vectors coming from southern regions $[23,24,79,80]$. Since recent decades, there are 6 species of mosquitoes and 1 species of biting midges of tropical origin colonizing different parts of Europe. Most of these species are involved in the transmission of various human and animal diseases and could be responsible for the introduction of some of these infections in Europe. For example, the tropical biting midges Culicoides imicula introduced the bluetongue virus of ruminants widely throughout Europe [81]. Introduced new mosquito species could serve as competent vectors both for locally already transmitting Plasmodium spp. and for exotic blood parasite species carried by long-distance avian migrants. Several field and experimental studies indicated that for instance Culex sasai and Culex pipiens pallens are competent vectors for some genetic lineages of Plasmodium in Asian regions [82, 83]. The introduction of these or other mosquito species from Asia or SE Asia could contribute to transmission of some avian Plasmodium parasites, including those which are at present not transmitted in Europe, like P. collidatum. However, precise experimental and field studies are needed to determine the possibility of such assumptions.

\section{Conclusions}

In conclusion, a new avian malaria parasite $P$. collidatum n. sp. (pFANTAIL01) was described, which is an incongruous species for European local birds and its transmission takes place in South, SE Asia and Oceania regions. $P$. collidatum completes development in the Eurasian siskin, which is a short-distance migrant within Europe. The parasite develops high intensities of parasitaemia and exoerythrocytic stages in the lungs, liver, spleen and kidneys of the vertebrate host. The negative effect on host health is not expressed in changed body mass and haematocrit values of experimentally infected birds, but this Plasmodium species is highly virulent causing the death of infected birds. Although common vector species of avian malaria, $C x$. pipiens form molestus and $C x$. quinquefasciatus were not susceptible to $P$. collidatum, this parasite should be considered as potential threat to siskins and likely to other non-migrating European birds if suitable vectors and ecological conditions appear.

\section{Abbreviations \\ SE: Southeast Asia; RBC: Red blood cell; Dpi: Days post inoculation; Dpe: Days post exposure.}

\section{Acknowledgements}

The authors are grateful to the whole team of a field site "Fringilla" of the BS "Rybachy" for species identification and bird ringing, as well as to the former director of Biological Station "Rybachy" Dr. Nikita Chernetsov for providing the necessary facilities for the experimental work. Authors thank Dr. Gediminas Valkiunnas for consultations on morphological description of the parasite and 
Maria Erokhina for helping in laboratory and maintenance of experimental birds.

\section{Authors' contributions}

Design of the experiment: EP, VP, JA, AM; Fieldwork: VP, EP, JA, AM; Birds caring and feeding: JA; Experiment performing: EP, VP, JA, AM; Morphological description of the parasite: Tl; Mosquitoes infection and sporogony preparations analysis: EP; Histology preparations and description: Ml; Molecular work and phylogenetic analysis: EP, JA; Statistical analysis: EP, AM; Paper writing: EP, VP, MI, AM. Paper reading and approval: All authors. All authors read and approved the final manuscript.

\section{Funding}

This study was supported by Russian Science Foundation (20-14-00049, Andrey Mukhin), Lithuanian Research Council (S-MIP-20-25, Rita Žiegytė) and PhD fellowship of Lithuanian Research Council (DSP-doc for Elena Platonova).

\section{Availability of data and materials}

All obtained data are available after email inquiry.

\section{Ethics approval}

All parts of this study were carried out in strict accordance with the current laws of Lithuania and Russia. The catching of wild birds, collection of samples and experiment procedure were approved by the International Research Co-operation Agreement between the Biological Station "Rybachy" of the Zoological Institute of the Russian Academy of Sciences and Nature Research Centre (25-05-2010). The permission for performing the experiment with birds in Russia was obtained from the ethical committee of Zoological Institute of Russian Academy of Science (permission number 2019-02-05-2/1). All effort was put in when handling birds and insects were made to reduce their suffering.

\section{Consent for publication}

Not applicable.

\section{Conflict of Interest}

The Authors declare no competent interests.

\section{Author details}

1 Biological Station Rybachy of the Zoological Institute, Russian Academy of Sciences, Kaliningrad Region 238535 Rybachy, Russia. ${ }^{2}$ Nature Research Centre, Akademijos 2, LT-09412 Vilnius 21, Lithuania.

Received: 2 November 2020 Accepted: 8 January 2021

Published online: 10 February 2021

\section{References}

1. Hahn S, Bauer S, Liechti F. The natural link between Europe and Africa-2.1 billion birds on migration. Oikos. 2009;118:624-6.

2. Beaudoin RL, Applegate JE, Davis DE, McLean RG. A model for the ecology of avian malaria. J Wildl Dis. 1971;7:5-13.

3. Ricklefs RE, Medeiros M, Ellis VA, Svensson-Coelho M, Blake JG, Loiselle BA, et al. Avian migration and the distribution of malaria parasites in New World passerine birds. J Biogeogr. 2017;44:1113-23.

4. Valkiūnas G. Avian malaria parasites and other Haemosporidia. Boca Raton: CRC; 2005.

5. Bennett G, Peirce M, Ashford R. Avian haematozoa: mortality and pathogenicity. J Nat Hist. 1993;27:993-1001.

6. Atkinson CT, Thomas NJ, Hunter DB. Parasitic diseases of wild birds. Oxford: Wiley-Blackwell; 2008.

7. Marzal A. Recent advances in studies on avian malaria parasites. In: Okwa OO editor, Malaria parasites. Rijeka: InTech; 2012. pp. 135-58.

8. Palinauskas V, la Puente JM, Hernández-Soto SR, Marzal A. Experimental parasitology and ecoimmunology: concepts and opportunities in avian haemosporidian studies. In: Santiago-Alarcon D, Marzal A. Eds; Avian Malaria and Related Parasites in the Tropics. Cham: Springer; 2020. pp. 527-58.

9. Palinauskas V, Žiegytè R, lezhova TA, Ilgūnas M, Bernotienè R, Valkiūnas G. Description, molecular characterisation, diagnostics and life cycle of
Plasmodium elongatum (lineage pERIRUB01), the virulent avian malaria parasite. Int J Parasitol. 2016;46:697-707.

10. Ilgūnas M, Bukauskaitè D, Palinauskas V, lezhova T, Fragner K, Platonova E, et al. Patterns of Plasmodium homocircumflexum virulence in experimentally infected passerine birds. Malar J. 2019;18:174.

11. Bensch S, Waldenström J, Jonzén N, Westerdahl H, Hansson B, Sejberg $\mathrm{D}$, et al. Temporal dynamics and diversity of avian malaria parasites in a single host species. J Anim Ecol. 2007;76:112-22.

12. Valkiūnas $G$, Ilgūnas $M$, Bukauskaitè $D$, Žiegytè $R$, Bernotienè $R$, Jusys $V$, et al. Plasmodium delichoni n. sp.: description, molecular characterisation and remarks on the exoerythrocytic merogony, persistence, vectors and transmission. Parasitol Res. 2016;115:2625-36.

13. Ilgūnas M, Palinauskas V, lezhova TA, Valkiūnas G. Molecular and morphological characterization of two avian malaria parasites (Haemosporida: Plasmodiidae), with description of Plasmodium homonucleophilum n. sp. Zootaxa. 2013;3666:49-61.

14. Palinauskas V, Žiegytė $R$, Ilgūnas $M$, lezhova TA, Bernotienè A, Bolshakov $C$, et al. Description of the first cryptic avian malaria parasite, Plasmodium homocircumflexum n. sp. with experimental data on its virulence and development in avian hosts and mosquitoes. Int J Parasitol. 2015;45:51-62

15. Valkiūnas $G$, Zehtindjiev $P$, Hellgren $O$, Ilieva M, lezhova TA, Bensch S Linkage between mitochondrial cytochrome $b$ lineages and morphospecies of two avian malaria parasites, with a description of Plasmodium (Novyella) ashfordi sp. nov. Parasitol Res. 2007;100:1311-22.

16. Zink G, Bairlein F. Der Zug Europäischer Singvögel, Ein Atlas der Wiederfunde Beringter Vögel, Vol 3. Wiesbaden: AULA-Verlag GmbH; 1995.

17. Bensch S, Hellgren O, Perez-Tris J. MalAvi: a public database of malaria parasites and related haemosporidians in avian hosts based on mitochondrial cytochrome $b$ lineages. Mol Ecol Resour. 2009;19:1353-8.

18. Synek P, Albrecht T, Vinkler M, Schnitzer J, Votýpka J, Munclinger P. Haemosporidian parasites of a European passerine wintering in South Asia: diversity, mixed infections and effect on host condition. Parasitol Res. 2013;112:1667-77.

19. Dimitrov D, Zehtindjiev P, Bensch S. Genetic diversity of avian blood parasites in SE Europe: cytochrome $b$ lineages of the genera Plasmodium and Haemoproteus (Haemosporida) from Bulgaria. Acta Parasitol. 2010;55:201-9.

20. Križanauskienè A, Hellgren $O$, Kosarev V, Sokolov L, Bensch S, Valkiūnas G. Variation in host specificity between species of avian hemosporidian parasites: evidence from parasite morphology and cytochrome $b$ gene sequences. J Parasitol. 2006;92:1319-24.

21. Hellgren $\mathrm{O}$. The occurrence of haemosporidian parasites in the Fennoscandian bluethroat (Luscinia svecica) population. J Ornithol. 2005;146:55-60.

22. Garamszegi LZ. Climate change increases the risk of malaria in birds. Glob Chang Biol. 2011;17:1751-9.

23. Medlock JM, Hansford KM, Schaffner F, Versteirt V, Hendrickx G, Zeller $\mathrm{H}$, et al. A review of the invasive mosquitoes in Europe: ecology, public health risks, and control options. Vector Borne Zoonotic Dis. 2012;12:435-47.

24. Martínez-de la Puente J, Muñoz J, Capelli G, Montarsi F, Soriguer R, Arnoldi D, et al. Avian malaria parasites in the last supper: identifying encounters between parasites and the invasive Asian mosquito tiger and native mosquito species in Italy. Malar J. 2015;14:32.

25. Martínez-de la Puente J, May RM, Huang X, Huang D, Liang Y, Zhang L, et al. Do invasive mosquito and bird species alter avian malaria parasite transmission? Diversity. 2020;12:111

26. Valkiūnas G, Ilgūnas M, Bukauskaitè D, Palinauskas V, Bernotienè R, lezhova TA. Molecular characterization and distribution of Plasmodium matutinum, a common avian malaria parasite. Parasitology. 2017;144:1726-35.

27. Mantilla JS, González AD, Valkiūnas G, Moncada LI, Matta NE. Description and molecular characterization of Plasmodium (Novyella) unalis sp. nov. from the Great Thrush (Turdus fuscater) in highland of Colombia. Parasitol Res. 2013;112:4193-204.

28. Palinauskas V, Valkiūnas G, Bolshakov VC, Bensch S. Plasmodium relictum (lineage P-SGS1): effects on experimentally infected passerine birds. Exp Parasitol. 2008;120:372-80.

29. Kazlauskienè R, Bernotienè R, Palinauskas $V$, lezhova TA, Valkiūnas G. Plasmodium relictum (lineages PSGS1 and pGRW11): complete 
synchronous sporogony in mosquitoes Culex pipiens pipiens. Exp Parasitol. 2013;133:454-61.

30. Žiegytè R, Bernotienè R, Bukauskaitè D, Palinauskas V, lezhova TA, Valkiūnas G. Complete sporogony of Plasmodium relictum (lineages PSGS1 and pGRW11) in mosquito Culex pipiens pipiens form molestus, with implications to avian malaria epidemiology. J Parasitol. 2014;100:878-82.

31. Godfrey RD, Fedynich AM, Pence DB. Quantification of hematozoa in blood smears. J Wildl Dis. 1987;23:558-65.

32. Sambrook J, Fritsch EF, Mamiatis T. Molecular cloning: a laboratory manual. 2nd ed. New York: Cold Spring Harbor Laboratory Press; 1989

33. Waldenström J, Bensch S, Hasselquist D, Ostman O. A new nested polymerase chain reaction method very efficient in detecting Plasmodium and Haemoproteus infections from avian blood. J Parasitol. 2004;90:191-4.

34. Hellgren O, Waldenström J, Bensch S. A new PCR assay for simultaneous studies of Leucocytozoon, Plasmodium, and Haemoproteus from avian blood. J Parasitol. 2004;90:797-802.

35. Hall A. BioEdit: a user-friendly biological sequence alignment editor and analysis program of Windows 95/98/NT. Nucleic Acids Symp Ser. 1999:41:95-8.

36. NCBI BLAST. Rockville Pike BMD. USA. 2019. https://blast.ncbi.nIm.nih. gov/Blast.cgi. Accessed $2 \mathrm{Jul} 2020$

37. Ronquist F, Huelsenbeck JP. MrBayes 3: Bayesian phylogenetic inference under mixed models. Bioinformatics. 2003;19:1572-4.

38. Nylander JAA. MrModeltest v2. Program distributed by the author. Upsala: Evolutionary Biology Centre, Uppsala University; 2004

39. Rambaut A. FigTree. Tree Figure Drawing Tool Version 1.4.4. 2006-2012. Institute of Evolutionary Biology, University of Edinburgh. http://tree.bio ed.ac.uk/software/figtree/. Accessed 2 Jul 2020.

40. Kumar S, Stecher G, Tamura K. MEGA7: molecular evolutionary genetics analysis version 7.0 for bigger datasets. Mol Biol Evol. 2016;33:1870-4.

41. R Core Team. R: a language and environment for statistical computing Vienna: R Foundation for Statistical Computing; 2019. http://www.R-proje ct.org/. Accessed 20 December 2019.

42. Beadell JS, Gering E, Austin J, Dumbacher JP, Peirce MA, Pratt TK, et al. Prevalence and differential host-specificity of two avian blood parasite genera in the Australo-Papuan region. Mol Ecol. 2004;13:3829-44.

43. Silva-Iturriza A, Ketmaier V, Tiedemann R. Prevalence of avian haemosporidian parasites and their host fidelity in the central Philippine islands. Parasitol Int. 2012;61:650-7.

44. Clark NJ, Clegg SM, Klaassen M. Migration strategy and pathogen risk: non-breeding distribution drives malaria prevalence in migratory waders. Oikos. 2016;125:1358-68.

45. Pérez-Rodríguez A, de la Puente J, Onrubia A, Pérez-Tris J. Molecular characterization of haemosporidian parasites from kites of the genus Milvus (Aves: Accipitridae). Int J Parasitol. 2013:43:381-7.

46. Zamora-Vilchis I, Williams SE, Johnson CN. Environmental temperature affects prevalence of blood parasites of birds on an elevation gradient: implications for disease in a warming climate. PLoS One. 2012;7:e39208.

47. Eastwood JR, Peacock L, Hall ML, Roast M, Murphy SA, Gonçalves A, et al, IJP: Parasites and wildlife persistent low avian malaria in a tropical species despite high community prevalence. IJP Parasites Wildl. 2019;8:88-93.

48. Martinsen ES, Perkins SL, Schall JJ. A three-genome phylogeny of malaria parasites (Plasmodium and closely related genera): evolution of lifehistory traits and host switches. Mol Phylogenet Evol. 2008;47:261-73.

49. Clark NJ, Olsson-pons S, Ishtiaq F, Clegg SM. Specialist enemies, generalist weapons and the potential spread of exotic pathogens : malaria parasites in a highly invasive bird. Int J Parasitol. 2015;45:891-99.

50. Dimitrov D, Marinov MP, Bobeva A, llieva M, Bedev K, Zehtindjiev P. Haemosporidian parasites and leukocyte profiles of pre-migratory rosy starlings (Pastor roseus) brought into captivity. Anim Migr. 2019;6:41-8.

51. Gupta P, Vishnudas CK, Ramakrishnan U, Robin W, Dharmarajan G. Geographical and host species barriers differentially affect generalist and specialist parasite community structure in a tropical sky-island archipelago. Proc Biol Sci. 2019;286:20190439.

52. Clark NJ, Clegg SM. The influence of vagrant hosts and weather patterns on the colonization and persistence of blood parasites in an island bird. J Biog. 2016;42:641-51.
53. Verwey JK, Peters A, Monks D, Raidal SR. Spillover of avian haemosporidian parasites (Haemosporidia: Plasmodium) and death of captive psittacine species. Aust Vet J. 2018:96:93-7.

54. Pornpanom P, Chagas CR, Lertwatcharasarakul P, Kasorndorkbua C, Valkiūnas G, Salakij C. Molecular prevalence and phylogenetic relationship of Haemoproteus and Plasmodium parasites of owls in Thailand: data from a rehabilitation centre. Int J Parasitol Parasites Wildl. 2019;9:248-57.

55. Manwell RD. How many species of avian malaria parasites are there? Am J Trop Med. 1935;15:265-83.

56. Chagas CRF, Valkiūnas G, Nery CVC, Henrique PC, Gonzalez IHL, Monteiro EF, et al. Plasmodium (Novyella) nucleophilum from an Egyptian Goose in São Paulo Zoo, Brazil: microscopic confirmation and molecular characterization. Int J Parasitol Parasites Wildl. 2013;2:286-91.

57. Manwell RD, Sessler GJ. Plasmodium paranucleophilum n. sp. from a South American tanager. J Protozool. 1971;18:629-32.

58. Bensch S, Inumaru M, Sato Y, Lee Cruz L, Cunningham AA, Goodman SJ, et al. Contaminations contaminate common databases. Mol Ecol Resour. 2020. doi:https://doi.org/10.1111/1755-0998.13272.

59. Levin II, Zwiers P, Deem SL, Geest EA, Higashiguchi JM, lezhova TA, et al. Multiple lineages of avian malaria parasites (Plasmodium) in the Galapagos Islands and evidence for arrival via migratory birds. Conserv Biol. 2013;27:1366-77.

60. Garnham PCC. Malaria parasites and other Haemosporidia. Oxford: Blackwell; 1966.

61. Valkiūnas $\mathrm{G}$, lezhova $\mathrm{T}$. Exo-erythrocytic development of avian malaria and related haemosporidian parasites. Malar J. 2017;16:101.

62. Manwell RD, Sessler GJ. Malaria parasites of toucans. J Protozool. 1971;18:570-4

63. Ilgūnas M, Bukauskaitè D, Palinauskas V, lezhova TA, Dinhopl N, Nedorost $\mathrm{N}$, et al. Mortality and pathology in birds due to Plasmodium (Giovannolaia) homocircumflexum infection, with emphasis on the exoerythrocytic development of avian malaria parasites. Malar J. 2016;15:256.

64. Atkinson CT, Woods KL, Dusek RJ, Sileo LS, Iko WM. Wildlife disease and conservation in Hawaii: pathogenicity of avian malaria (Plasmodium relictum) in experimentally infected liwi (Vestiaria coccinea). Parasitology. 1995:111:59-69.

65. Atkinson CT, Duset RJ, Woods KL, Iko WM. Pathogenicity of avian malaria in experimentally-infected Hawaii Amakihi. J Wildl Dis. 2000;36:197-204.

66. Palinauskas V, Žiegytè R, Šengaut J, Bernotiene R. Different paths-the same virulence: experimental study on avian single and co-infections with Plasmodium relictum and Plasmodium elongatum. Int J Parasitol. 2018:48:1089-96.

67. lezhova TA, Valkiūnas G, Bairlein F. Vertebrate host specificity of two avian malaria parasites of the subgenus Novyella: Plasmodium nucleophilum and Plasmodium vaughani. J Parasitol. 2005;91:472-4.

68. Zehtindjiev P, Ilieva M, Westerdahl H, Hansson B, Valkiunas G, Bensch S. Dynamics of parasitemia of malaria parasites in a naturally and experimentally infected migratory songbird, the great reed warbler Acrocephalus arundinaceus. Exp Parasitol. 2008;119:99-110.

69. Dimitrov D, Palinauskas V, lezhova TA, Bernotienè R, llgūnas $M$, Bukauskaite $\mathrm{D}$, et al. Plasmodium spp.: an experimental study on vertebrate host susceptibility to avian malaria. Exp Parasitol. 2015;148:1-16.

70. Corradetti A, Scanga M. Plasmodium (Novyella) vaughani subsp. merulae, n subsp, parassita di Turdus merula, con descrizione del ciclo pre-eritrocitico. Parassitologia. 1972;14:85-93.

71. Mukhin A, Palinauskas V, Platonova E, Kobylkov D, Vakoliuk I, Valkiūnas G. The strategy to survive primary malaria infection: an experimental study on behavioural changes in parasitized birds. PLoS One. 2016;11:e0159216

72. Palinauskas V, Platonova E, Žiegytè R, Mukhin A. Dynamics of blood stage and sporozoite-induced malarial infections in experimentally infected passerines. Int J Parasitol. 2020. doi:https://doi.org/10.1016/j.jpar a.2020.05.015.

73. Williams RB. Avian malaria: clinical and chemical pathology of Plasmodium gallinaceum in the domesticated fowl Gallus gallus. Avian Pathol. 2005;34:29-47.

74. Fuller T, Bensch S, Muller I, Novembre J, Perez-Tris J, Ricklefs RE, Smith TB, Waldenstrom J. The ecology of emerging infectious diseases in migratory birds: an assessment of the role of climate change and priorities for future research. EcoHealth. 2012;9:80-8.

75. Valkiūnas $G$, Žiegytè R, Palinauskas V, Bernotienè R, Bukauskaitè D, Ilgūnas $\mathrm{M}$, et al. Complete sporogony of Plasmodium relictum (lineage pGRW4) 
in mosquitoes Culex pipiens pipiens, with implications on avian malaria epidemiology. Parasitol Res. 2015;114:3075-85.

76. Martínez-de la Puente J, Ferraguti M, Ruiz S, Roiz D, Soriguer RC, Figuerola J. Culex pipiens forms and urbanization: effects on blood feeding sources and transmission of avian Plasmodium. Malar J. 2016;15:589.

77. Samy AM, Elaagip AH, Kenawy MA, Ayres CF, Peterson AT, Soliman DE. Climate change influences on the global potential distribution of the mosquito Culex quinquefasciatus, vector of West Nile virus and lymphatic filariasis. PLoS One. 2016;11:e0163863.

78. Reiter ME, LaPointe DA. Landscape factors influencing the spatial distribution and abundance of mosquito vector Culex quinquefasciatus (Diptera: Culicidae) in a mixed residential-agricultural community in Hawaii. J Med Entomol. 2007:44:861-8.

79. Bradshaw CJA, Leroy B, Bellard C, Roiz D, Albert C, Fournier A, et al. Massive yet grossly underestimated global costs of invasive insects. Nat Commun. 2016;7:12986

80. Cunze S, Koch LK, Kochmann J, Klimpel S. Aedes albopictus and Aedes japonicus - two invasive mosquito species with different temperature niches in Europe. Parasit Vectors. 2016;9:573.
81. Mellor PS, Boorman J, Baylis M. Culicoides biting midges: their role as arbovirus vectors. Annu Rev Entomol. 2000;45:307-40.

82. Kim K, Tsuda Y, Sasaki T, Kobayashi M, Hirota Y. Mosquito blood-meal analysis for avian malaria study in wild bird communities: laboratory verification and application to Culex sasai (Diptera: Culicidae) collected in Tokyo, Japan. Parasitol Res. 2009;05:1351.

83. Ejiri H, Sato Y, Kim KS, Hara T, Tsuda Y, Imura T, et al. Entomological study on transmission of avian malaria parasites in zoological garden in Japan: bloodmeal identification and detection of avian malaria parasite DNA from blood-fed mosquitoes. J Med Entomol. 2011;48:600-7.

\section{Publisher's note}

Springer Nature remains neutral with regard to jurisdictional claims in published maps and institutional affiliations.
Ready to submit your research? Choose BMC and benefit from:

- fast, convenient online submission

- thorough peer review by experienced researchers in your field

- rapid publication on acceptance

- support for research data, including large and complex data types

- gold Open Access which fosters wider collaboration and increased citations

- maximum visibility for your research: over $100 \mathrm{M}$ website views per year

At BMC, research is always in progress.

Learn more biomedcentral.com/submissions 